\title{
Sensitivity of Intertropical Convergence Zone Movement to the Latitudinal Position of Thermal Forcing
}

\author{
JEONGBin SEO AND SARAH M. KANG \\ School of Urban and Environmental Engineering, Ulsan National Institute of Science and Technology, Ulsan, South Korea \\ DARGAN M. W. FRIERSON \\ Department of Atmospheric Sciences, University of Washington, Seattle, Washington
}

(Manuscript received 13 November 2013, in final form 24 January 2014)

\begin{abstract}
A variety of recent studies have shown that extratropical heating anomalies can be remarkably effective at causing meridional shifts in the intertropical convergence zone (ITCZ). But what latitudinal location of forcing is most effective at shifting the ITCZ? In a series of aquaplanet simulations with the GFDL Atmospheric Model, version 2 (AM2), coupled to a slab mixed layer ocean, it is shown that high-latitude forcing actually causes a larger shift in the ITCZ than when equivalent surface forcing is applied in the tropics. Equivalent simulations are run with an idealized general circulation model (GCM) without cloud and water vapor feedbacks, also coupled to an aquaplanet slab ocean, where the ITCZ response instead becomes weaker the farther the forcing is from the equator, indicating that radiative feedbacks must be important in AM2.

In the absence of radiative feedbacks, the tendency for anomalies to decrease in importance the farther away they are from the equator is due to the quasi-diffusive nature of energy transports. Cloud shortwave responses in AM2 act to strengthen the ITCZ response to extratropical forcing, amplifying the response as it propagates toward the equator. These results emphasize the great importance of the extratropics in determining the position of the ITCZ.
\end{abstract}

\section{Introduction}

Much of the precipitation in the tropics occurs within a narrow zonal band of high rainfall known as the intertropical convergence zone (ITCZ). Because small changes in the position of the ITCZ can greatly perturb local precipitation, it is important to understand how the ITCZ may respond to external thermal forcing.

While the ITCZ is often thought to be controlled by tropical mechanisms (e.g., Xie 2004), recent studies that have demonstrated that the ITCZ can respond to heating well outside the tropics have drawn significant attention. For example, the marine ITCZ shifts away from the hemisphere with increasing high-latitude ice cover (Chiang and Bitz 2005). The double ITCZ problem of general circulation models (GCMs) has been demonstrated

Corresponding author address: Sarah M. Kang, School of Urban and Environmental Engineering, Ulsan National Institute of Science and Technology, 100 Banyeon-ri, Eonyang-eup, Ulsan 689798, South Korea.

E-mail: skang@unist.ac.kr to be largely caused by cloud biases over the Southern Ocean (Hwang and Frierson 2013). A global southward shift of precipitation in the late twentieth century has been shown to be driven by sulfate aerosols emissions from the Northern Hemisphere (NH) midlatitudes (Rotstayn and Lohmann 2002; Hwang et al. 2013). In contrast, the ITCZ shifts toward the hemisphere with increases in absorbing aerosols such as black carbon (Roberts and Jones 2004; Yoshimori and Broccoli 2008; Mahajan et al. 2013). The sensitivity of the ITCZ to extratropical forcings has been interpreted using an energetic framework (Kang et al. 2008, hereafter K08; Kang et al. 2009; Yoshimori and Broccoli 2009).

The ITCZ has also been shown to shift in response to changes in the surface flux induced by ocean circulation changes. For example, a shutdown of Atlantic meridional overturning circulation (AMOC) results in a large decrease in the ocean-to-atmosphere flux in the high latitudes of the NH, and causes a southward ITCZ shift in coupled GCMs (Zhang and Delworth 2005, Stouffer et al. 2006). Fučkar et al. (2013) studied an idealized coupled GCM and found that the direction of cross-equatorial 
(a) $\mathrm{H}$

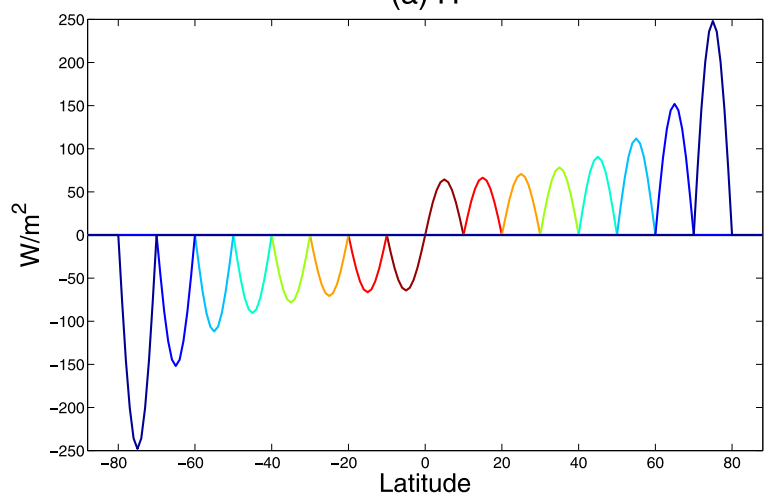

(b) $F_{0}$

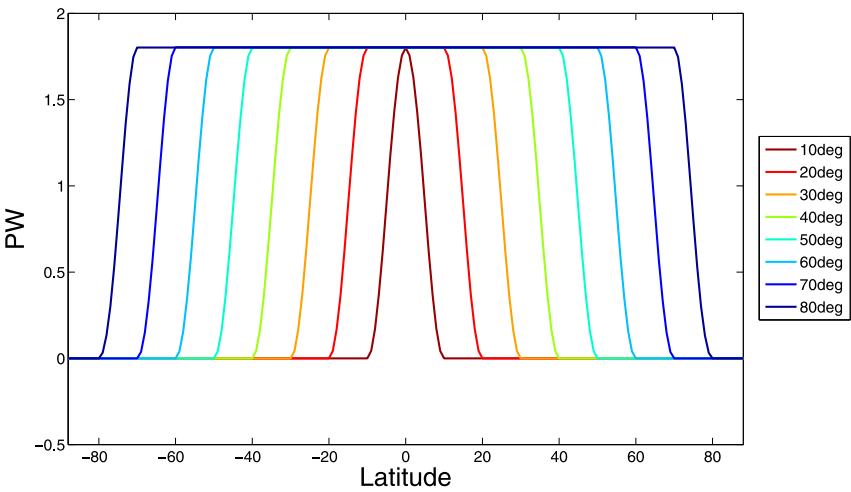

FIG. 1. (a) Latitudinal distribution of imposed surface forcing $H\left(\mathrm{~W} \mathrm{~m}^{-2}\right)$ and (b) implied south-to-north oceanic energy transport $F_{o}(\mathrm{PW})$.

heat transport by AMOC controls the ITCZ location. Frierson et al. (2013) built upon this argument, showing that the AMOC is the primary reason that the ITCZ exists in the $\mathrm{NH}$ in the present climate.

The large sensitivity of the ITCZ to surface heat flux anomalies even in the high latitudes begs the question of what meridional locations are most effective at shifting the ITCZ. In this paper, we study this question by forcing aquaplanet GCMs with surface heating anomalies at different latitudes, and studying the response of the ITCZ.

\section{Data and methods}

We employ two aquaplanet GCMs with different levels of complexity. One is a comprehensive atmospheric GCM developed at the Geophysical Fluid Dynamics Laboratory (GFDL), Atmospheric Model, version 2 (AM2; Anderson et al. 2004). The model uses a horizontal resolution of $2^{\circ}$ latitude $\times 2.5^{\circ}$ longitude with 24 vertical levels, and is run under equinox conditions. The other is the gray radiation moist (GRaM) GCM (Frierson et al. 2006) in which the radiative fluxes are only a function of temperature. Hence, there are no water vapor- and cloudradiative feedbacks. It has $\mathrm{T} 42$ horizontal resolution with 25 vertical levels. Both models are coupled to an aquaplanet slab mixed layer ocean of 2.4-m depth. The shallow mixed layer is used to shorten the time to reach equilibrium. The models are run for 8 years with the results shown averaged over the last 6 years.

The experiments are designed to examine the efficiency of surface thermal forcing on shifting the ITCZ depending on its meridional position. The control climate with no flux adjustment is perturbed by prescribing heating in the mixed layer in the $\mathrm{NH}$ and cooling of equal magnitude in the Southern Hemisphere (SH; Fig. 1a). The meridional position of thermal forcing $H$ with $10^{\circ}$ latitudinal width is systematically varied as follows:

$H=-A \sin \left[\frac{\pi}{10^{\circ}}\left(\theta+\theta_{0}\right)\right]$ for $-\theta_{0}<\theta<-\theta_{0}+10^{\circ}$,

$H=-A \sin \left[\frac{\pi}{10^{\circ}}\left(\theta-\theta_{0}\right)\right]$ for $\theta_{0}-10^{\circ}<\theta<\theta_{0}, \quad$ and $H=0 \quad$ elsewhere.

Since the global mean of $H$ is zero, it can be described in terms of an implied meridional oceanic heat transport (OHT) $F_{o}$, with $H=-\left(1 / 2 \pi a^{2} \cos \theta\right)\left(\partial F_{o} / \partial \theta\right)$, as shown in Fig. 1b. In all of the experiments, $F_{o}$ is positive, equivalent to a south-to-north OHT. We vary $\theta_{0}$ from $10^{\circ}$ to $80^{\circ}$ while adjusting the maximum amplitude of the forcing $A$ to ensure that the cross-equatorial flux $F_{o}$ is fixed to $1.8 \mathrm{PW}$. The sensitivity of the results to the magnitude of the thermal forcing is examined by performing the same set of experiments with half the amplitude, equivalent to a cross-equatorial flux of $0.9 \mathrm{PW}$. Our results are qualitatively insensitive to $A$, so for brevity all the figures (except Fig. 3) are for $F_{o}=1.8 \mathrm{PW}$.

\section{Results}

The zonal-mean precipitation between $30^{\circ} \mathrm{S}$ and $30^{\circ} \mathrm{N}$ in both models is shown in Figs. $2 \mathrm{a}$ and $2 \mathrm{~b}$. The tropical precipitation shifts toward the warmer $\mathrm{NH}$ in response not only to tropical thermal forcing but also to extratropical thermal forcing, consistent with previous studies (e.g., Broccoli et al. 2006; K08). This behavior is different in the two models however. In GRaM, tropical precipitation is perturbed more effectively by tropical thermal forcing (Fig. 2a), whereas AM2 is perturbed more effectively by extratropical thermal forcing (Fig. 2b). This 
GRaM

(a)

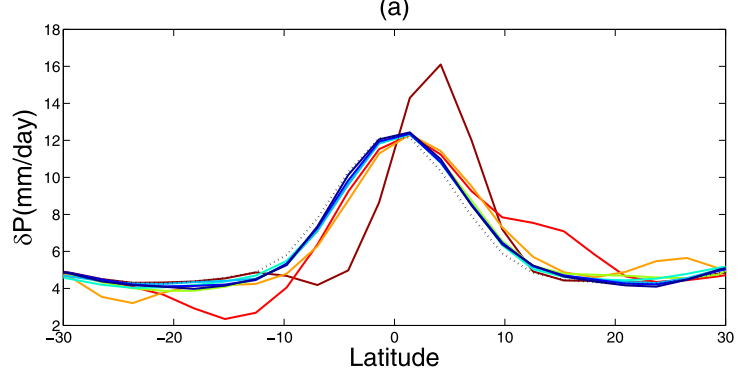

(c)

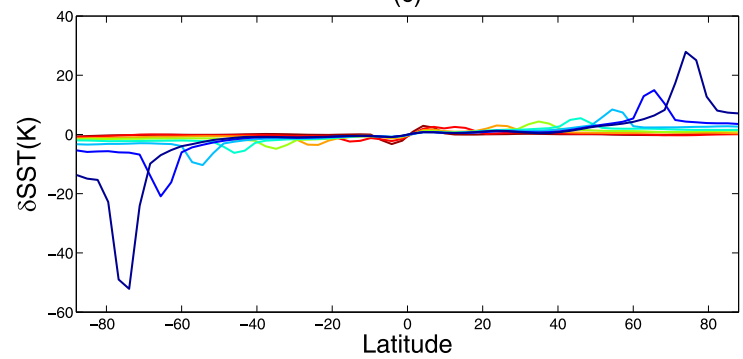

AM2

(b)

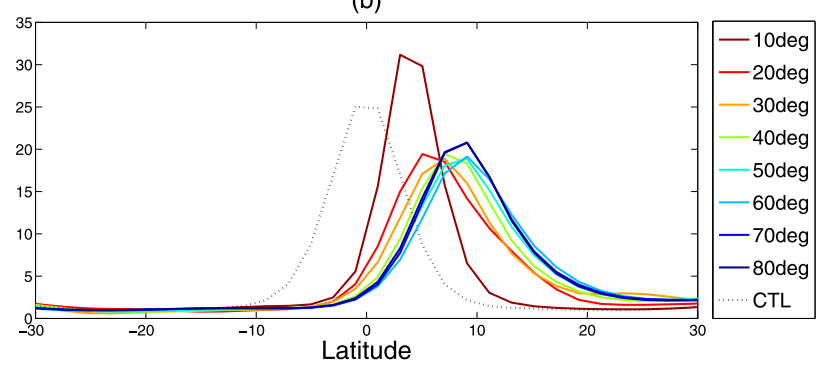

(d)

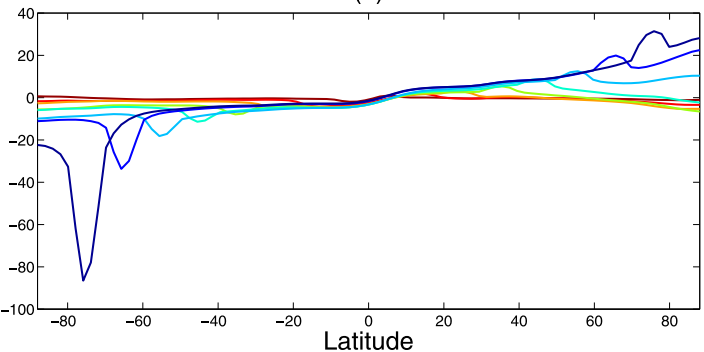

FIG. 2. The zonal-mean (a),(b) precipitation $\left(\mathrm{mm} \mathrm{day}^{-1}\right)$ between $30^{\circ} \mathrm{S}$ and $30^{\circ} \mathrm{N}$ and (c),(d) the change in sea surface temperature (SST; K) in (left) GRaM and (right) AM2. The legend indicates $\theta_{0}$.

stark difference is better shown in Fig. 3a, which shows the latitude of the ITCZ for varying $\theta_{0}$ in both models. The largest displacement of the ITCZ occurs when $\theta_{0}=10^{\circ}$ in GRaM and when $\theta_{0}=60^{\circ}$ in AM2. Figure 3 a also shows that the displacement of the ITCZ is larger in AM2 than in GRaM for all cases, a fact that was previously attributed to the presence of water vapor and cloud feedbacks in AM2 in Kang et al. (2009).

The ITCZ response is closely linked to the response of the cross-equatorial atmospheric energy transport (K08). The energy budget for the atmospheric column in steady state is $R_{\mathrm{TOA}}-\nabla \cdot F_{o}=\nabla \cdot F_{A}$, where $R_{\mathrm{TOA}}$ is the top-of-atmosphere (TOA) net radiation and $F_{A}=[m v]$ is the zonal and time mean meridional transport of moist static energy $m$. A change in cross-equatorial atmospheric energy transport (AET) is typically accomplished by an anomalous Hadley circulation (HC), which also transports moisture across the equator in the opposite direction. We express the change in deep tropical AET as a compensation $C$ of the imposed oceanic flux by the AET; that is, $C \equiv\left|\left(F_{A}-F_{\text {ctl }}\right) / F_{o}\right|$. Indeed, the degree of compensation $C$ averaged between $5^{\circ} \mathrm{S}$ and $5^{\circ} \mathrm{N}$ (Fig. 3c) is proportional to the strength of the anomalous HC at the equator (Fig. 3b). In GRaM, $C$ becomes smaller as the external thermal forcing is located farther away from the tropics, consistent with the smaller ITCZ response. In contrast, $C$ in AM2 becomes larger as the external thermal forcing is located outside of the tropics, consistent with the displacement of the ITCZ. When AM2 is compared with GRaM, one can find that $C$ is much greater in AM2 for all cases with one exception when $\theta_{0}=10^{\circ}$.

To understand the dependence of $C$ on $\theta_{0}$, we express $R_{\mathrm{TOA}}$ as the divergence of a flux $F_{\mathrm{TOA}}$ such that $R_{\mathrm{TOA}}=-\nabla \cdot \delta F_{\mathrm{TOA}}$. Further, after subtracting the global mean, $F_{\text {TOA }}$ can be divided into a clear-sky component, $F_{\text {clr }}$, and a component from cloud radiative forcing (CRF), $F_{\mathrm{CRF}}$ (i.e., $F_{\mathrm{TOA}}=F_{\text {clr }}+F_{\mathrm{CRF}}$ with $\left.\mathrm{CRF}=-\nabla \cdot \delta F_{\mathrm{CRF}}\right)$. Then the anomalous energy budget, with the global mean removed, can be represented as

$$
-\nabla \cdot \delta F_{\mathrm{clr}}-\nabla \cdot \delta F_{\mathrm{CRF}}-\nabla \cdot \delta F_{o}=\nabla \cdot \delta F_{A},
$$

where $\delta$ denotes the difference from the control run $(A=0)$. Each term in Eq. (2) for the cases with $\theta_{0}=10^{\circ}$ (tropical forcing) and $80^{\circ}$ (extratropical forcing) is shown in Fig. 4 for GRaM (top) and AM2 (bottom). Since large temperature gradients cannot be sustained in the tropics (e.g., Sobel et al. 2001; Yano and Bonazzola 2009), the tropical thermal forcing in GRaM, where $R_{\mathrm{TOA}}$ is a function of temperature only, is mostly compensated by atmospheric energy transport divergence with only a small change in TOA radiative fluxes (Fig. 4a). That is, there is large compensation $C$ in response to tropical thermal forcing. In contrast, extratropical thermal forcing induces large temperature changes (Fig. 2c) and large meridional gradients of $\delta F_{\text {TOA }}$ in the extratropics (Fig. 4b). Locally, the imposed warming over $70^{\circ}-80^{\circ} \mathrm{N}$ is balanced mostly by the divergence of atmospheric energy transport $\left(\nabla \cdot \delta F_{A}\right.$ is large positive) and partly by 
(a) ITCZ

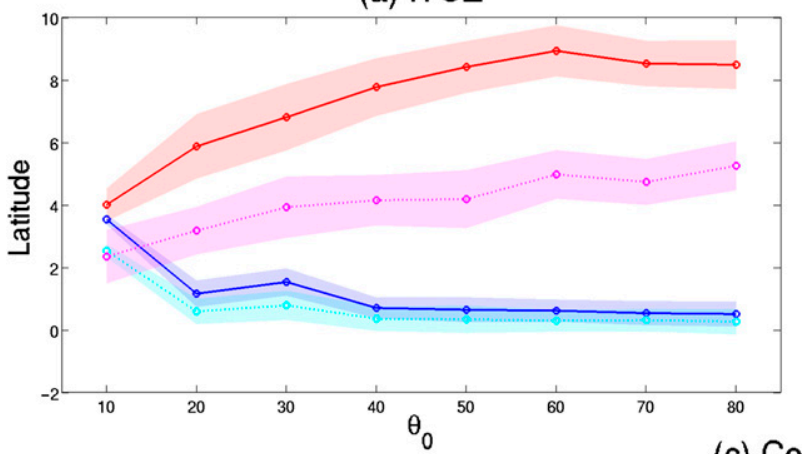

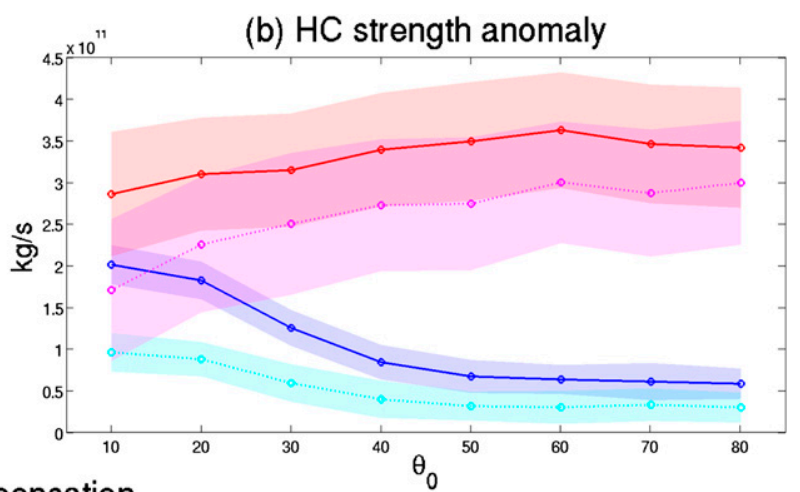

(c) Compensation

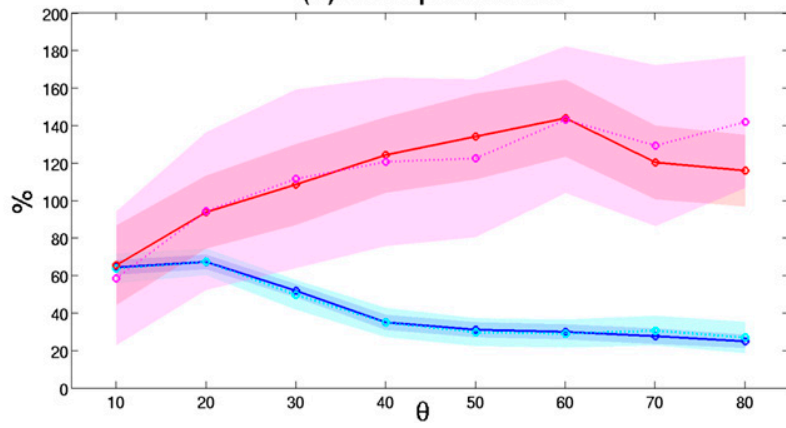

$\rightarrow$ GRaM

GRaM-half

$\rightarrow$ AM2

- AM2-half

FIG. 3. (a) The location of the ITCZ, obtained by differentiating the precipitation with respect to latitude and linearly interpolating to find the zero crossing, (b) the strength of anomalous Hadley circulation at the equator at $500 \mathrm{hPa}$, and (c) the degree of compensation $C$ $(\%)$, averaged equatorward of $5^{\circ}$, for GRaM (blue) and AM2 (red). Dashes indicate the result of half the amplitude and shading indicates one standard deviation $(\sigma)$.

increasing outgoing longwave radiation (OLR) via warming the atmosphere $\left(\nabla \cdot \delta F_{\mathrm{TOA}}\right.$ is modestly positive), as shown later (in Figs. 6a and 6e). The atmospheric column outside of the forced region (e.g., $\left.20^{\circ}-70^{\circ} \mathrm{N}\right)$ is warmed by quasi-diffusive AET, but loses energy by increased OLR from the warmer atmosphere. Because of weak tropical temperature gradients, $\delta F_{\mathrm{TOA}}$, which is a function of temperature only in GRaM, must be flat within the deep tropics $\left(20^{\circ} \mathrm{S}-20^{\circ} \mathrm{N}\right)$, and so is $\delta F_{A}$. In other words, as the NH subtropics become warmer and the $\mathrm{SH}$ subtropics become colder, the $\mathrm{HC}$ tries to remove this interhemispheric temperature contrast in the tropics by transporting energy toward the colder $\mathrm{SH}$. Hence, the compensation $C$ in the tropics is determined by $\delta F_{A}$ at the poleward edge of the HC. The magnitude of the signal reaching the subtropics is controlled by the quasidiffusive eddy energy fluxes, and is thus larger when the forcing is closer to the tropics. This explains why the compensation $C$, and accordingly the ITCZ response, is greater in response to tropical thermal forcing than to extratropical thermal forcing in GRaM.

By comparing Figs. $4 \mathrm{~b}$ and $4 \mathrm{~d}$, one can see that changes in CRF in AM2 act to amplify the imposed extratropical thermal forcing by more than $100 \%$ in the tropics. This is because, as shown in Fig. 5, the extratropical thermal forcing increases (decreases) lowlevel cloud amount in the cooled (warmed) region, possibly via stabilization (destabilization) of the lower troposphere, leading to more cooling (warming) through the feedback of cloud forcing on TOA energy fluxes. Extratropical cloud responses that amplify the effective strength of the extratropical thermal forcing cause the compensation $C$ and the ITCZ response to be significantly larger in AM2 than in GRaM. In particular, the imposed thermal forcing is overcompensated by the AET when $\theta_{0}>20^{\circ}$ (Fig. 3c). This result is consistent with Zhang et al. (2010), in which the extratropical lowcloud feedback is shown to amplify the ITCZ response to a weakened AMOC in a fully coupled model, GFDL Climate Model, version 2.1 (CM2.1).

In contrast to the extratropical cloud responses, the tropical cloud responses associated with the ITCZ shift acts to counteract the imposed thermal forcing in AM2: the changes in CRF in all cases in Fig. 5a exhibit cooling (warming) in the $\mathrm{NH}(\mathrm{SH})$ tropics. This is because, in AM2, the shortwave forcing following the ITCZ shift is larger than the longwave forcing associated with high cloud amount changes (Kang et al. 2014). Hence, when the thermal forcing is located in the tropics, cloud effects act to counteract the imposed forcing (Fig. 4c). Because 
(a) $\operatorname{GRaM}\left(\theta_{0}=10\right)$

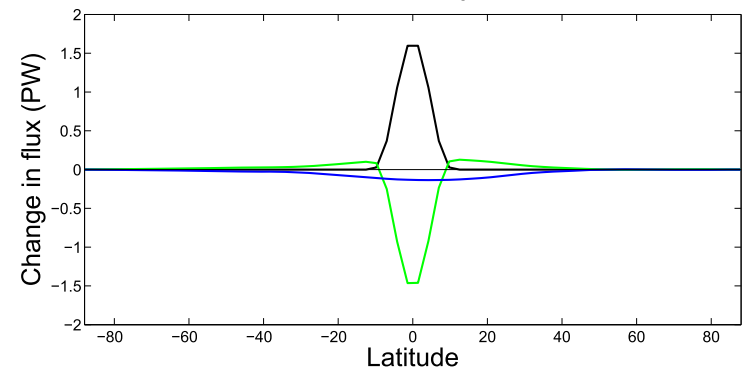

(c) $\operatorname{AM} 2\left(\theta_{0}=10\right)$

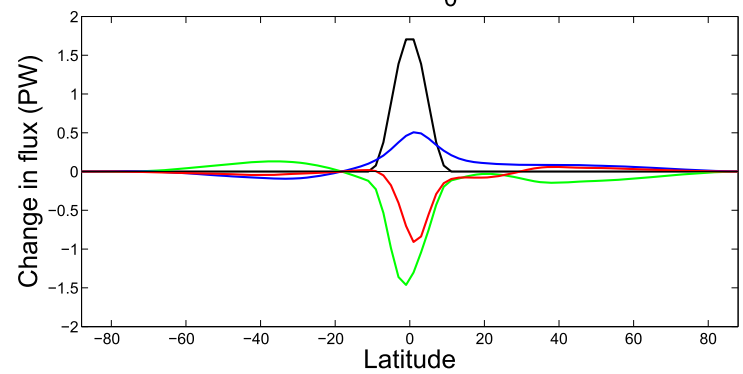

(b) $\operatorname{GRaM}\left(\theta_{0}=80\right)$

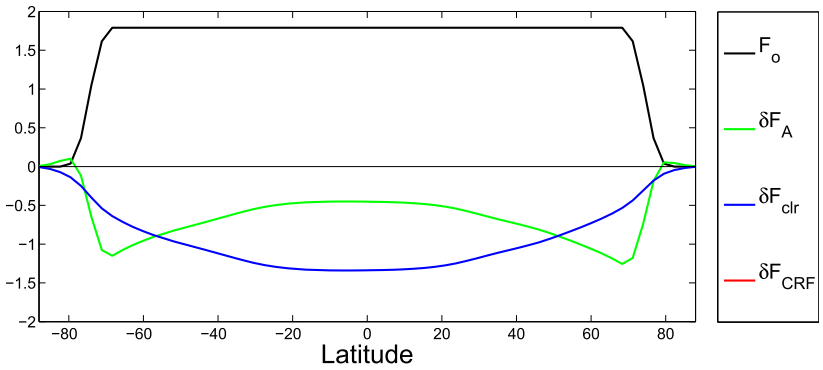

(d) $\operatorname{AM} 2\left(\theta_{0}=80\right)$

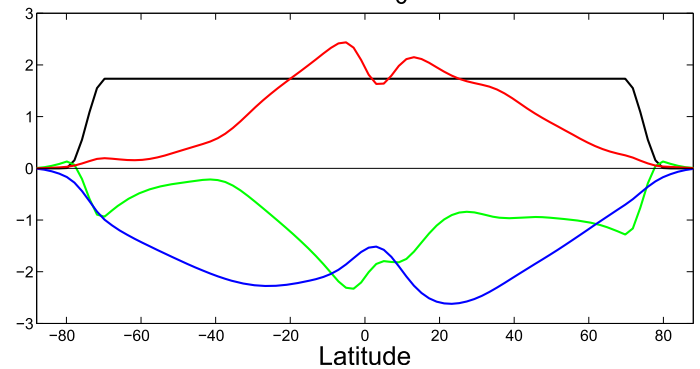

FIG. 4. The change in atmospheric energy transport $\delta F_{A}$ (green), the imposed oceanic flux (black), and the flux by the change $F_{o}$ in cloud radiative forcing $\delta F_{\mathrm{CRF}}$ (red) and clear-sky radiation $\delta F_{\text {clr }}$ (blue) for (a),(c) $\theta_{0}=10^{\circ}$ and (b),(d) $\theta_{0}=80^{\circ}$ in (top) GRaM and (bottom) AM2. Unit in petawatt.

of these opposing effects of cloud responses on altering the effective strength of the imposed forcing in the tropical and extratropical forcing cases, the compensation $C$ in the tropics in AM2 becomes larger as the forcing is located farther away from the equator. If only these cloud effects were to cause the difference between the tropical and extratropical forcing cases, the difference of $C$ between the two cases should have been much greater than that shown in Fig. 3. For instance, differences in $\delta F_{\mathrm{CRF}}$ in Figs. $4 \mathrm{c}$ and $4 \mathrm{~d}$ indicate that the cloud effects of the case

(a) $\delta \mathrm{CRF}$

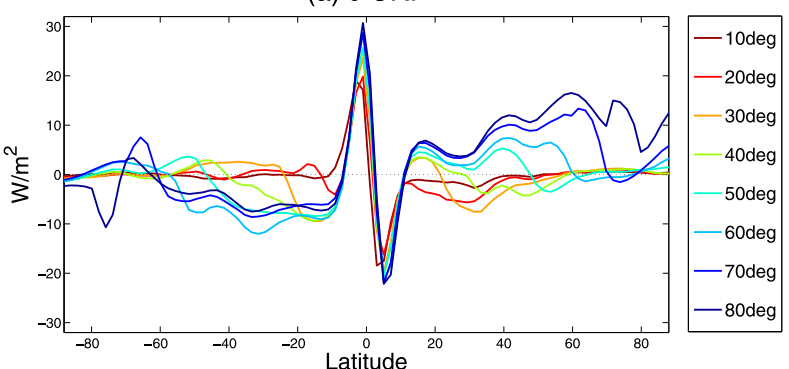

(b) $\delta$ High cld amt

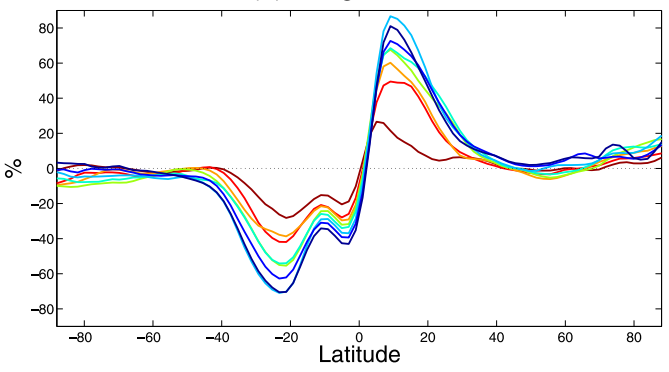

(c) $\delta$ Low cld amt

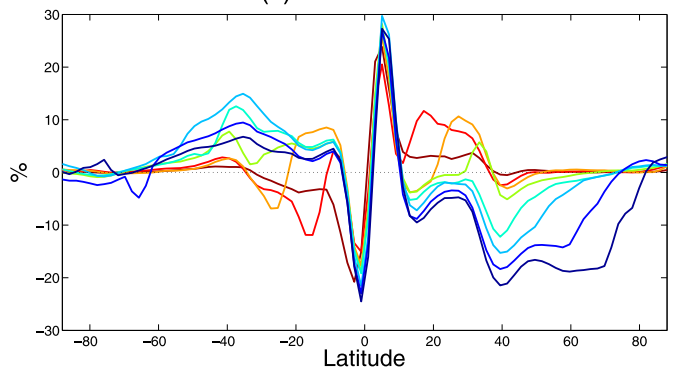

FIG. 5. The zonal-mean change in (a) cloud radiative forcing $\left(\mathrm{W} \mathrm{m}^{-2}\right),(\mathrm{b})$ high cloud amount (\%), and (c) low cloud amount (\%) in AM2. 
GRaM

(a)

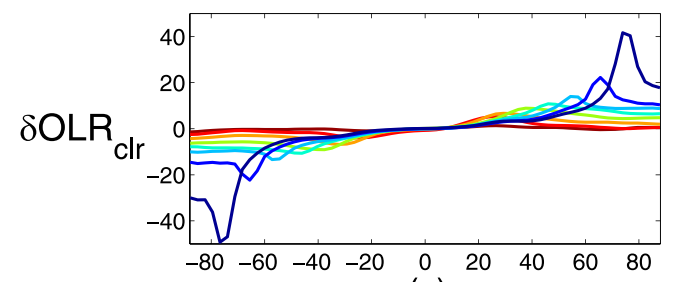

(c)

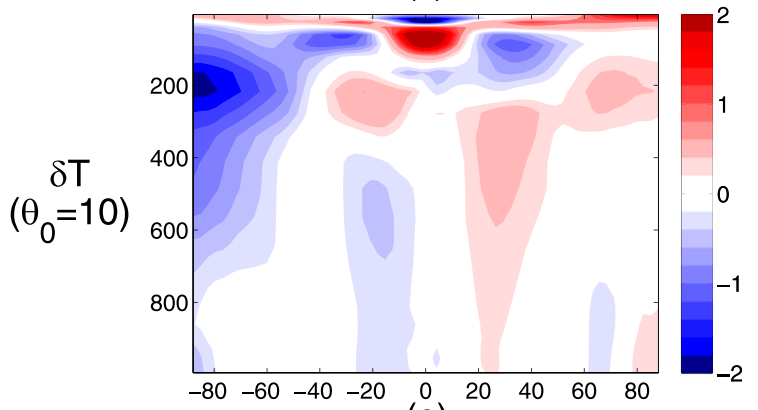

(e)

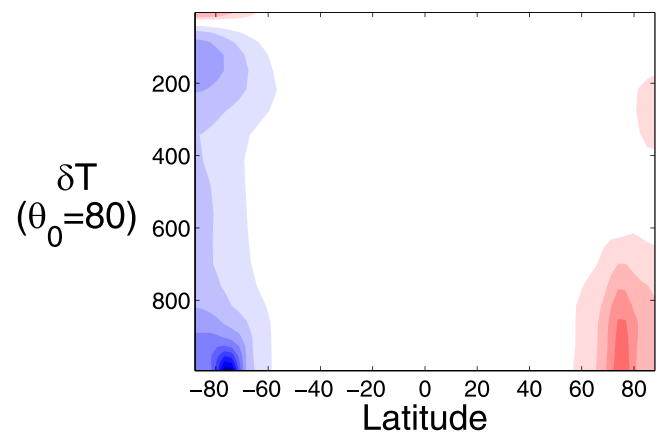

AM2

(b)

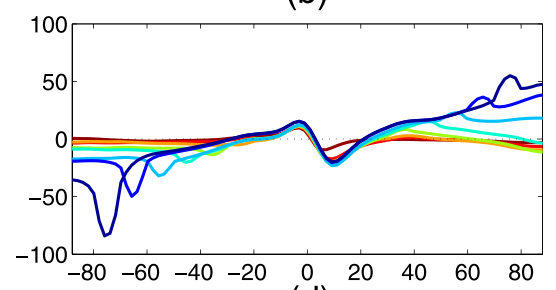

(d)

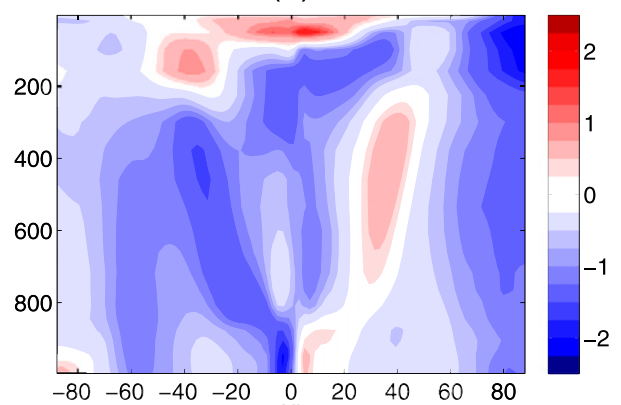

(f)
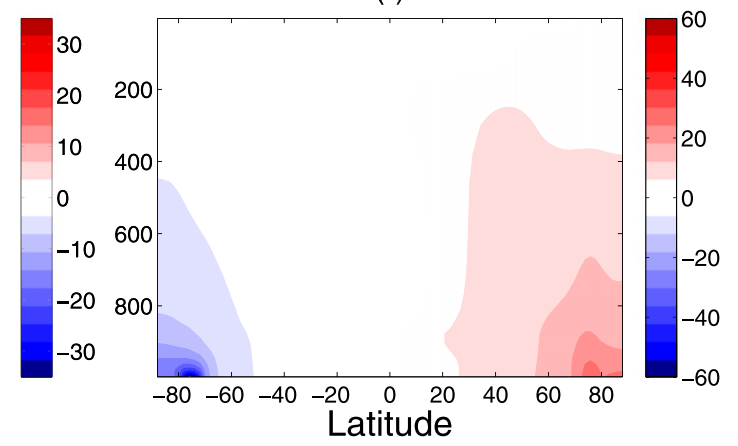

FIG. 6. The zonal-mean change in (a),(b) clear-sky OLR $\left(\mathrm{W} \mathrm{m}^{-2}\right)$ and temperature (K) for (c),(d) $\theta_{0}=10^{\circ}$ and (e),(f) $\theta_{0}=80^{\circ}$ in (left) GRaM and (right) AM2.

with $\theta_{0}=80^{\circ}$ amplify the effective strength of imposed forcing at the equator by $2.7 \mathrm{PW}$ more compared with $\theta_{0}=10^{\circ}$ case. This would result in $150 \%$ larger $C$, but in fact $C$ is larger by $50 \%$. This is because larger changes in the clear-sky radiative fluxes have an opposing effect on compensation in the extratropical forcing cases (Fig. $4 d)$, which we investigate next.

The upper panels in Fig. 6 show the clear-sky OLR response $\left(\delta \mathrm{OLR}_{\mathrm{clr}}\right)$. In $\mathrm{GRaM}, \mathrm{OLR}_{\mathrm{clr}}$ is only a function of temperature, so that it increases in the warmed $\mathrm{NH}$ and decreases in the cooled $\mathrm{SH}$. As the external thermal forcing is imposed farther away from the tropics, $\delta \mathrm{OLR}_{\mathrm{clr}}$ becomes larger. In particular, $\delta \mathrm{OLR}_{\mathrm{clr}}$ in the forced region is 40 times larger when $\theta_{0}=80^{\circ}$ than when $\theta_{0}=10^{\circ}$ (Fig. 6a). In AM2, the sign of $\delta \mathrm{OLR}_{\text {clr }}$ is reversed in the tropics. Figures $6 \mathrm{~d}$ and $6 \mathrm{f}$ show that in the warmed northern tropics, there is cooling response above $850 \mathrm{hPa}$, possibly due to large negative CRF (Fig. 5a), so that $\mathrm{OLR}_{\mathrm{clr}}$ is reduced there. In the cooled southern tropics, the temperature decreases throughout the troposphere but the effective emission level is possibly lowered due to reduction in specific humidity, leading to increase in $\mathrm{OLR}_{\mathrm{clr}}$. This flipped sign can be also seen in Figs. $4 \mathrm{c}$ and $4 \mathrm{~d}$ where $\nabla \cdot \delta F_{\text {clr }}$ is positive (negative) in the southern (northern) tropics.

The larger $\delta \mathrm{OLR}_{\mathrm{clr}}$ in the higher-latitude forcing cases is in part, but not entirely, due to the stronger local forcing applied in order to keep the areaweighted heating the same. It is also because the tropical forcing cannot be balanced largely by $\mathrm{OLR}_{\mathrm{clr}}$ due to weak temperature gradients in the tropics, whereas the extratropical forcing is balanced more by OLR $_{\text {clr }}$ where large temperature gradients can be sustained (Fig. 6). Large temperature changes in the extratropical forcing case cause the clear-sky radiative fluxes to act as a limiter on the ITCZ response, diminishing the positive feedback from cloud responses (Fig. $4 d)$. This effect is especially significant when the thermal 
forcing is imposed in the polar regions $\left(\theta_{0}>60^{\circ}\right)$, so that the displacement of the ITCZ in AM2 slightly decreases when $\theta_{0}>60^{\circ}$.

\section{Conclusions}

In this study, we examine the efficiency of surface thermal forcing in different latitudinal locations on shifting the ITCZ using two aquaplanet GCMs, the comprehensive GFDL AM2 and an idealized moist GCM, GRaM. In GRaM, the displacement of the ITCZ is larger when the thermal forcing is located closer to the tropics, because the impact of the thermal forcing outside the tropics diminishes on its way equatorward by quasi-diffusive transport of energy. In contrast, in AM2, extratropical thermal forcing can shift the ITCZ even more than tropical thermal forcing. In AM2, low cloud responses substantially amplify the effective strength of extratropical thermal forcing. However, extratropical thermal forcing causes local temperature to change much more compared with tropical thermal forcing, thereby enhancing the response of clear-sky radiative fluxes. In AM2, the positive feedback from the cloud effects overwhelm the negative feedback from clear-sky radiative fluxes; hence, extratropical forcing is more effective at shifting the ITCZ than tropical forcing.

The results from AM2 are the more applicable ones to Earth's climate; the simulations with GRaM, lacking water vapor and cloud radiative feedbacks, were run to understand the role of dynamical processes versus radiative feedbacks. Thus our study suggests that extratropical factors can be even more important than local tropical processes in displacing the ITCZ. The strong influence of the extratropics on tropical precipitation can be seen in Coupled Model Intercomparison Project phase 3 (CMIP3) simulations of global warming (Frierson and Hwang 2012). Because there are large uncertainties in cloud feedback, which primarily results from low clouds (Soden and Held 2006; Zelinka et al. 2013), our results should be tested in other GCMs. Also, it is important to note that despite the importance of extratropical forcing in shifting the zonal mean ITCZ, local tropical forcing is much more effective at causing zonal asymmetries in tropical precipitation (Kang et al. 2014).

Acknowledgments. We thank three anonymous reviewers for their constructive comments, which greatly helped to improve an earlier version of the manuscript. S. M. Kang is supported by the 2013 Creativity and Innovation Research Fund 1.130033 of Ulsan National Institute of Science and Technology (UNIST).

\section{REFERENCES}

Anderson, J. L., and Coauthors, 2004: The new GFDL global atmosphere and land model AM2-LM2: Evaluation with prescribed SST simulations. J. Climate, 17, 4641-4673, doi:10.1175/ JCLI-3223.1.

Broccoli, A. J., K. A. Dahl, and R. J. Stouffer, 2006: Response of the ITCZ to Northern Hemisphere cooling. Geophys. Res. Lett., 33, L01702, doi:10.1029/2005GL024546.

Chiang, J. C., and C. M. Bitz, 2005: Influence of high latitude ice cover on the marine intertropical convergence zone. Climate Dyn., 25, 477-496, doi:10.1007/s00382-005-0040-5.

Frierson, D. M. W., and Y.-T. Hwang, 2012: Extratropical influence on ITCZ shifts in slab ocean simulations of global warming. J. Climate, 25, 720-733, doi:10.1175/ JCLI-D-11-00116.1.

, I. M. Held, and P. Zurita-Gotor, 2006: A gray-radiation aquaplanet moist GCM. Part I: Static stability and eddy scale. J. Atmos. Sci., 63, 2548-2566, doi:10.1175/JAS3753.1.

—_, and Coauthors, 2013: Contribution of ocean overturning circulation to tropical rainfall peak in the Northern Hemisphere. Nat. Geosci., 6, 940-944, doi:10.1038/ ngeo1987.

Fučkar, N. S., S.-P. Xie, R. Farneti, E. A. Maroon, and D. M. W. Frierson, 2013: Influence of the extratropical ocean circulation on the intertropical convergence zone in an idealized coupled general circulation model. J. Climate, 26, 4612-4629, doi:10.1175/JCLI-D-12-00294.1.

Hwang, Y.-T., and D. M. W. Frierson, 2013: Link between the double-intertropical convergence zone problem and cloud biases over the Southern Ocean. Proc. Natl. Acad. Sci. USA, 110, 4935-4940, doi:10.1073/pnas.1213302110.

,-- , and S. M. Kang, 2013: Anthropogenic sulfate aerosol and the southward shift of tropical precipitation in the late 20th century. Geophys. Res. Lett., 40, 2845-2850, doi:10.1002/ grl.50502.

Kang, S. M., I. M. Held, D. M. W. Frierson, and M. Zhao, 2008: The response of the ITCZ to extratropical thermal forcing: Idealized slab-ocean experiments with a GCM. J. Climate, 21, 3521-3532, doi:10.1175/2007JCLI2146.1.

, D. M. W. Frierson, and I. M. Held, 2009: The tropical response to extratropical thermal forcing in an idealized GCM: The importance of radiative feedbacks and convective parameterization. J. Atmos. Sci., 66, 2812-2827, doi:10.1175/ 2009JAS2924.1.

, I. M. Held, and S.-P. Xie, 2014: Contrasting the tropical responses to zonally asymmetric extratropical and tropical thermal forcing. Climate Dyn., doi:10.1007/s00382-013-1863-0, in press.

Mahajan, S., K. J. Evans, J. J. Hack, and J. E. Truesdale, 2013: Linearity of climate response to increases in black carbon aerosols. J. Climate, 26, 8223-8237, doi:10.1175/ JCLI-D-12-00715.1.

Roberts, D. L., and A. Jones, 2004: Climate sensitivity to black carbon aerosol from fossil fuel combustion. J. Geophys. Res., 109, D16202, doi:10.1029/2004JD004676.

Rotstayn, L. D., and U. Lohmann, 2002: Tropical rainfall trends and the indirect aerosol effect. J. Climate, 15, 2103-2116, doi:10.1175/1520-0442(2002)015<2103:TRTATI>2.0.CO;2.

Sobel, A. H., J. Nilsson, and L. M. Polvani, 2001: The weak temperature gradient approximation and balanced tropical moisture waves. J. Atmos. Sci., 58, 3650-3665, doi:10.1175/ 1520-0469(2001)058<3650:TWTGAA $>2.0 . \mathrm{CO} ; 2$. 
Soden, B. J., and I. M. Held, 2006: An assessment of climate feedbacks in coupled ocean-atmosphere models. J. Climate, 19, 3354-3360, doi:10.1175/JCLI3799.1.

Stouffer, R., and Coauthors, 2006: Investigating the causes of the response of the thermohaline circulation to past and future climate changes. J. Climate, 19, 1365-1387, doi:10.1175/ JCLI3689.1.

Xie, S.-P., 2004: The shape of continents, air-sea interaction, and the rising branch of the Hadley circulation. The Hadley Circulation: Present, Past, and Future, H. F. Diaz and R. S. Bradley, Eds., Springer, 121-152.

Yano, J.-I., and M. Bonazzola, 2009: Scale analysis for large-scale tropical atmospheric dynamics. J. Atmos. Sci., 66, 159-172, doi:10.1175/2008JAS2687.1.

Yoshimori, M., and A. J. Broccoli, 2008: Equilibrium response of an atmosphere-mixed layer ocean model to different radiative forcing agents: Global and zonal mean response. J. Climate, 21, 4399-4423, doi:10.1175/2008JCLI2172.1.

— changes and radiative feedback processes. Geophys. Res. Lett., 36, L20703, doi:10.1029/2009GL040488.

Zelinka, M. D., S. A. Klein, K. E. Taylor, T. Andrews, M. J. Webb, J. M. Gregory, and P. M. Forster, 2013: Contributions of different cloud types to feedbacks and rapid adjustments in CMIP5. J. Climate, 26, 5007-5027, doi:10.1175/ JCLI-D-12-00555.1.

Zhang, R., and T. L. Delworth, 2005: Simulated tropical response to a substantial weakening of the Atlantic thermohaline circulation. J. Climate, 18, 1853-1860, doi:10.1175/JCLI3460.1.

, S. M. Kang, and I. M. Held, 2010: Sensitivity of climate change induced by the weakening of the Atlantic meridional overturning circulation to cloud feedback. J. Climate, 23, 378389, doi:10.1175/2009JCLI3118.1. 